\title{
Incidence of eye cancer in Taiwan: an 18-year review
}

\begin{abstract}
Purpose To describe the incidence and histologic patterns of eye cancers in Chinese in Taiwan.

Methods Beginning in 1979, cases of cancer in Taiwan were reported to the Taiwan National Cancer Registry. Information on all Chinese patients diagnosed with eye malignancies under the International Classification of Disease, Ninth Revision, site 190, was retrieved for analysis from the data bank of the Taiwan National Cancer Registry. Results In all, 733 cases with primary eye cancers were identified from 1979 to 1996, an 18-year period. The average annual agestandardized incidence of eye cancers was 2.46 per million population ( 2.57 for male and 2.33 for female). For cases less than 15 years of age, the most common eye malignancy was retinoblastoma $(86.0 \%)$, followed by rhabdomyosarcoma (3.9\%) and lymphoma (2.8\%). For cases 15 years of age or older, the most common eye malignancy was melanoma (28.6\%), followed by squamous cell sarcoma (21.0\%) and lymphoma (20.8\%).

Conclusions The time trends of the incidence of eye cancers were relatively stable over the 18-year period in Taiwan. Retinobalstoma, melanoma, and lymphoma were the three most common eye cancers in this Chinese population.

Eye (2004) 18, 152-158. doi:10.1038/

sj.eye. 6700619
\end{abstract}

Keywords: incidence; eye neoplasms; registries; Taiwan

2002

Accepted in revised form:

2 April 2003

This paper was presented in part as a poster at the American Academy of Ophthalmology Annual Meeting, Dallas, TX October 2000

Financial or proprietary interest: None
C-Y Cheng ${ }^{1,2,3}$ and W-M Hsu',

population. ${ }^{4,5}$ Of all of the malignant intraocular tumours, uveal melanoma was the most common one in white groups and other lightly pigmented racial groups. ${ }^{6}$ For other ethnic groups, the incidence of ocular melanoma or other eye malignancies was far less described. Although ocular melanoma was presumed to be rare in East Asians, precise population-based data are sparse. In Singapore, where the majority of residents are Chinese, Malay, and Indian, the most common eye malignancy was retinoblastoma, followed by melanoma and squamous cell carcinoma. ${ }^{7}$

The purpose of the study was to describe the incidence and histologic patterns of primary eye cancers in Chinese in Taiwan from 1979 to 1996, and to investigate age, temporal, and histologic variations in the incidence of eye cancers in the Chinese population.

\section{Methods}

Taiwan is situated off the southeastern coast of China, and has a land area of $36000 \mathrm{~km}^{2}$ and a total population of about 22 millions at the end of year 2001. The great majority (>99\%) of the citizens are Chinese people. Such a large and homogeneous population was sufficient to the proposed study, which investigated the rare eye malignancies.

In 1979, the Department of Health of Taiwan established a National Cancer Registry. Since then cases of cancer at each of Taiwan's hospitals with more than 50 beds were reported to the Registry. Hence information about the incidence of cancer was available and has been used in many cancer epidemiological studies. ${ }^{8-}$ ${ }^{10}$ In the National Cancer Registry, the items registered included the patient's name, national identification number, sex, age, date of diagnosis, location of tumours, and histologic data. Upon these data arrival at the Registry office, they are first checked for accuracy and completeness. If they were incomplete, they are returned to the reporting hospital, otherwise they are entered into computer files. 
Duplication could be checked and eliminated according to the national identification number, which is unique to each of residents in Taiwan.

We analysed information, retrieved from the data bank of the Taiwan National Cancer Registry between January 1979 and December 1996, and identified all cases of primary eye malignancies coded to International Classification of Diseases, Ninth Revision (ICD-9) ${ }^{11}$ site 190. Site 190 includes malignancies of eyeball (190.0), orbit (190.1), lacrimal gland (190.2), conjunctiva (190.3), cornea (190.4), retina (190.5), choroid (190.6), lacrimal duct (190.7), other specified sites of eye (190.8), and unspecified parts of eye (190.9). Cancers of the eyelids are not included in site 190. Histologic codes were assigned according to the International Classification of Disease for Oncology (ICD-O). ${ }^{12}$

For calculating incidence by year and sex, we used mid-year population counts based on the Taiwan-Fukien Demographic Fact Book, ${ }^{13}$ which is published yearly in Taiwan. These demographic data are highly accurate, because all births, deaths, marriages, and divorces in Taiwan must be registered with the government's household-registration offices. The records are doublechecked annually by registration officers, who conduct home visits. Average annual incidence rates were calculated for male and female individuals. To facilitate the comparison of rates across times and between countries, all rates were directly age-adjusted to the world standard population. ${ }^{14}$ To determine the incidence of primary malignancies and the relative frequencies of histologic types, only those cases with histologic verification were included. All data were analysed using a commercial statistical software package, Stata (Stata Corporation, College Station, TX, USA).

\section{Results}

From 1979 to 1996, a total of 889 primary eye cancers were diagnosed in this Chinese population. Of these, $733(82.3 \%)$ cases were histologically verified and were used for analysis, including 405 (55.2\%) men and 328 (44.8\%) women.

Figure 1 shows the average age-specific incidence of eye cancers in this population. There was a bimodal age distribution for both male and female populations, with a peak before the age of 5 years and the other in the later decades of life. For cases younger than 15 years of age, the most common eye malignancy was retinoblastoma $(86.0 \%)$, followed by rhabdomyosarcoma (3.9\%) and lymphoma (2.8\%) (Table 1). For cases 15 years of age or older, the most common eye malignancy was melanoma (28.6\%), followed by squamous cell carcinoma (21.0\%)

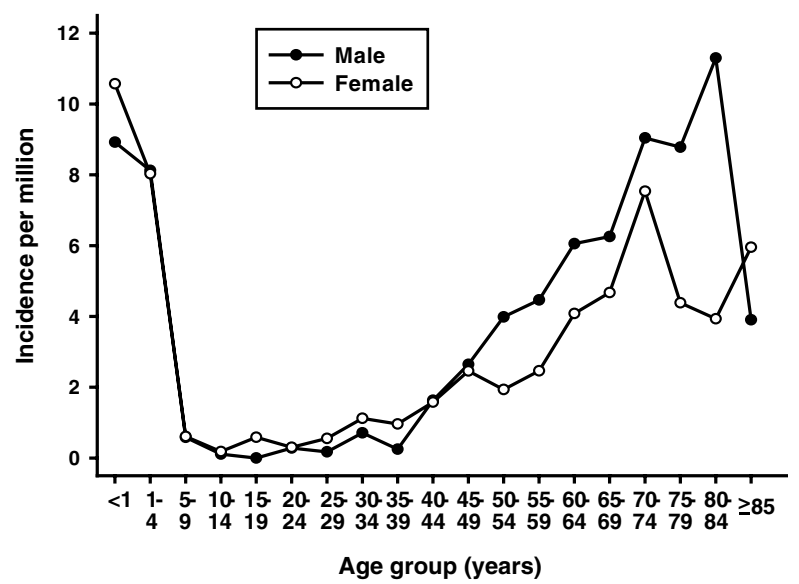

Figure 1 Average annual age-specific incidence of eye cancers in Taiwan from 1979 to $1996(n=733)$.

and lymphoma (20.8\%) (Table 2). Overall, retinoblastoma (259 of 733 cases, $35.3 \%$ ) was the most common eye malignancy in Taiwan, followed by melanoma (131 cases, $17.9 \%)$, lymphoma (101 cases, $13.8 \%$ ), and squamous cell carcinoma (95 cases, $13.0 \%$ ). Therefore, the first peak in Figure 1 may be attributed to the high frequency of retinoblastoma in those less than 15 years of age, while the second peak in the elderly group may correspond to other eye malignancies, such as squamous cell carcinoma and lymphoma.

Table 3 shows the number of cases by anatomical subsites of the eye malignancies and the most common malignancies in each specific subsite. Malignancies from retina (267 of 733 cases, $36.4 \%$ ), orbit (142 cases, $19.4 \%$ ), and conjunctiva (115 cases, $15.7 \%$ ) composed the majority of the tumours recorded.

The time trends in annual age-standardized incidence rates by sex are shown in Figure 2. The average annual age-standardized incidence of eye cancers was 2.46 per million population (95\% confidence interval (CI): 2.16 , 2.76 per million), with 2.57 per million for male (95\% CI: $2.22,2.91$ per million) and 2.33 per million for female populations (95\% CI: 1.94, 2.72 per million). The incidence rates were relatively stable over the 18-year period, although there was substantial annual variation.

Figures 3 and 4 shows the time trends in incidence of the four most common eye cancers. The average annual age-standardized incidence of retinoblastoma was 4.28 (95\% CI: 3.45, 5.12) per million and 7.68 (95\% CI: 6.19, 9.17) per million for children younger than 10 and 5 years, respectively, in this Chinese population. The average annual incidence of the other common eye cancers was 0.39 (95\% CI: $0.30,0.48)$ per million population for melanoma, 0.31 (95\% CI: 0.22, 0.40) per million for lymphoma, and 0.31 (95\% CI: 0.24, 0.39) per million for squamous cell carcinoma. 
Table 1 Histology of eye cancers in cases <15 years of age in Taiwan from 1979 to 1996

\begin{tabular}{|c|c|c|c|c|c|}
\hline \multirow[t]{2}{*}{ Histology } & \multicolumn{2}{|c|}{ Case } & \multirow{2}{*}{$\frac{\text { Sex }}{M: F}$} & \multicolumn{2}{|c|}{ Age (years) } \\
\hline & No. & Frequency (\%) & & Mean & Range \\
\hline Retinoblastoma & 246 & 86.0 & $124: 122$ & 1.7 & $0-10$ \\
\hline Rhabdomyosarcoma & 11 & 3.85 & $7: 4$ & 4.5 & $1-7$ \\
\hline Lymphoma & 8 & 2.80 & $4: 4$ & 5.5 & $1-13$ \\
\hline Neuroblastoma & 4 & 1.40 & $2: 2$ & 2.0 & $1-5$ \\
\hline Neoplasm, malignant & 4 & 1.40 & $1: 3$ & 2.5 & $0-4$ \\
\hline Melanoma & 3 & 1.05 & $2: 1$ & 8.0 & $3-13$ \\
\hline Others $^{\mathrm{a}}$ & 10 & 3.50 & & & \\
\hline Total & 286 & 100 & & & \\
\hline
\end{tabular}

ancluding squamous cell carcinoma, infantile fibrosarcoma, malignant fibrous histiocytoma, dermoid cyst with malignant transformation, reticulosarcoma, myeloid sarcoma, and carcinoma NOS.

Table 2 Histology of eye cancers in cases $\geq 15$ years of age in Taiwan from 1979 to 1996

\begin{tabular}{|c|c|c|c|c|c|}
\hline \multirow[t]{2}{*}{ Histology } & \multicolumn{2}{|c|}{ Case } & \multirow{2}{*}{$\frac{\text { Sex }}{M: F}$} & \multicolumn{2}{|c|}{ Age (years) } \\
\hline & No. & Frequency (\%) & & Mean & Range \\
\hline Melanoma & 128 & 28.6 & $58: 70$ & 50.9 & $15-85$ \\
\hline Squamous cell carcinoma & 94 & 21.0 & $57: 37$ & 63.7 & $21-88$ \\
\hline Lymphoma & 93 & 20.8 & $61: 32$ & 57.2 & $22-79$ \\
\hline Carcinoma NOS & 41 & 9.17 & $28: 13$ & 58.6 & $33-82$ \\
\hline Adenoid cystic carcinoma & 21 & 4.70 & $13: 8$ & 42.2 & $18-84$ \\
\hline Adenocarcinoma & 20 & 4.47 & $13: 7$ & 55.6 & $23-81$ \\
\hline Retinoblastoma & 13 & 2.91 & $8: 5$ & 59.0 & $37-81$ \\
\hline Neoplasm, malignant & 8 & 1.79 & $6: 2$ & 61.4 & $46-81$ \\
\hline Mixed tumour, malignant & 5 & 1.12 & $2: 3$ & 48.8 & $24-85$ \\
\hline Others $^{\mathrm{a}}$ & 24 & 5.37 & & & \\
\hline Total & 447 & 100 & & & \\
\hline
\end{tabular}

NOS = not otherwise specified. a Including papillary carcinoma, transitional cell carcinoma, mucoepidermoid carcinoma, mucinous adenocarcinoma, infiltrating duct carcinoma, medullary carcinoma, fibrosarcoma, malignant fibrous histiocytoma, malignant fibroxanthoma, rhabdomyosarcoma, neurofibrosarcoma, and reticulosarcoma.

\section{Discussion}

We present the epidemiological characteristics of eye cancers in Taiwan using data from the Taiwan National Cancer Registry, which encompasses the entire population of Taiwan Island. Review of the English literature using Medline revealed that this study provided the largest Chinese population in describing the epidemiological characteristics of eye cancers.

This study showed that the annual age-standardized incidence of eye cancers was 2.46 per million population in Taiwan. This is similar to the rate reported in Singapore, ${ }^{7}$ but was relatively lower than those reported from Western populations. Table 4 compares the agestandardized incidence of eye cancers among various countries and ethnic groups. ${ }^{1,2,7}$ The incidence of eye cancers in the Western populations ranged from 5.4 to 8.1 per million, while incidence was only 1.81 to 2.57 per million in East Asians. The observed lower incidence may be attributed to the lower incidence of malignant ocular melanoma in East Asians.

The time trend of the incidence of eye cancers was relatively stable over the 18-year period, although annual variation existed. There was great variation in the first 3 year from 1979 to 1981 . The effectiveness and compliance of reporting cases to the Taiwan National Cancer Registry at the beginning of the system may explain the observed variation. In the recent 10 years, although the change in incidence was not significant, the incidence appears to be an increase. Whether the incidence will really increase with years may need more years of observation in the future.

This study identified three most common eye malignancies as retinoblastoma (35.3\%), melanoma (17.9\%), and lymphoma (13.8\%), which were different from the report from Singapore ${ }^{7}-53.6 \%$ of retinoblastoma, $19.2 \%$ of melanoma, and $11.2 \%$ of squamous cell carcinoma, and the data of cancer registry in New York State ${ }^{1}-70.4 \%$ of melanoma, $9.8 \%$ of 
Table 3 Histology by anatomical subsites of eye cancers in Taiwan from 1979 to 1996

\begin{tabular}{|c|c|c|c|}
\hline Subsite & Histology & $\begin{array}{c}\text { No. } \\
\text { of } \\
\text { cases }\end{array}$ & $\begin{array}{c}\text { Frequency } \\
(\%)\end{array}$ \\
\hline \multirow[t]{4}{*}{ Eyeball $(190.0)^{\mathrm{a}}$} & Melanoma & 51 & 83.6 \\
\hline & Squamous cell carcinoma & 3 & 4.92 \\
\hline & Other cell types & 7 & 11.5 \\
\hline & Total histologically confirmed & 61 & 100 \\
\hline \multirow[t]{7}{*}{ Orbit $(190.1)^{\mathrm{b}}$} & Lymphoma & 59 & 41.5 \\
\hline & Squamous cell carcinoma & 19 & 13.4 \\
\hline & Rhabdomyosarcoma & 10 & 7.04 \\
\hline & Carcinoma NOS & 9 & 6.34 \\
\hline & Adenocarcinoma & 8 & 5.63 \\
\hline & Other cell types & 37 & 26.1 \\
\hline & Total & 142 & 100 \\
\hline \multirow{5}{*}{$\begin{array}{l}\text { Lacrimal } \\
\text { gland (190.2) }\end{array}$} & Adenoid cystic carcinoma & 14 & 45.2 \\
\hline & Lymphoma & 6 & 19.3 \\
\hline & Adenocarcinoma & 4 & 12.9 \\
\hline & Other cell types & 7 & 22.6 \\
\hline & Total & 31 & 100 \\
\hline \multirow{6}{*}{$\begin{array}{l}\text { Conjunctiva } \\
\text { (190.3) }\end{array}$} & Squamous cell carcinoma & 50 & 43.5 \\
\hline & Melanoma & 27 & 23.5 \\
\hline & Lymphoma & 23 & 20.0 \\
\hline & Carcinoma NOS & 12 & 10.4 \\
\hline & Other cell types & 3 & 2.60 \\
\hline & Total & 115 & 100 \\
\hline \multirow[t]{4}{*}{ Cornea (190.4) } & Squamous cell carcinoma & 4 & 44.5 \\
\hline & Carcinoma NOS & 3 & 33.3 \\
\hline & Other cell types & 2 & 22.2 \\
\hline & Total & 9 & 100 \\
\hline \multirow[t]{3}{*}{ Retina (190.5) } & Retinoblastoma & 259 & 97.0 \\
\hline & Other cell types & 8 & 3.00 \\
\hline & Total & 267 & 100 \\
\hline \multirow[t]{3}{*}{ Choroid (190.6) } & Melanoma & 32 & 88.9 \\
\hline & Other cell types & 4 & 11.1 \\
\hline & Total histologically confirmed & 36 & 100 \\
\hline \multirow{5}{*}{$\begin{array}{l}\text { Lacrimal } \\
\text { duct (190.7) }\end{array}$} & Carcinoma NOS & 4 & 28.6 \\
\hline & Squamous cell carcinoma & 3 & 21.4 \\
\hline & Adenocarcinoma & 3 & 21.4 \\
\hline & Other cell types & 4 & 28.6 \\
\hline & Total & 14 & 100 \\
\hline \multirow{6}{*}{$\begin{array}{l}\text { Other sites } \\
(190.8,190.9)^{c}\end{array}$} & Melanoma & 16 & 27.6 \\
\hline & Squamous cell carcinoma & 14 & 24.1 \\
\hline & Carcinomas NOS & 10 & 17.2 \\
\hline & Adenocarcinoma & 4 & 6.90 \\
\hline & Other cell types & 14 & 5.17 \\
\hline & Total & 58 & 100 \\
\hline
\end{tabular}

NOS = not otherwise specified. ${ }^{a} 190.0$ : ciliary body, sclera, crystalline lens, sclera, uveal tract and iris, but except conjunctiva, cornea, retina, and choroid. 190.1 : connective tissue of orbit, extraocular muscle, and retrobulbar tissue. ${ }^{c} 190.8$ : other specified sites of eye; 190.9: eye, part unspecified.

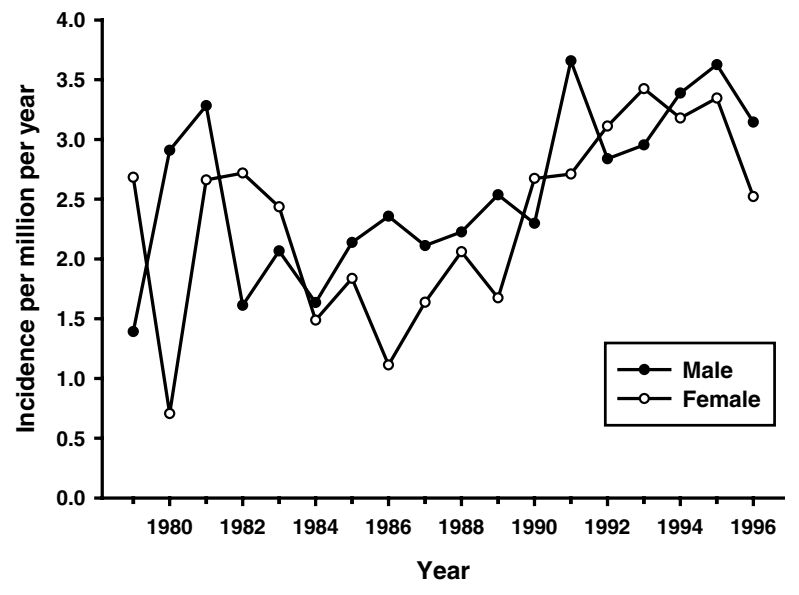

Figure 2 Age-standardized incidence of eye cancers in Taiwan from 1979 to $1996(n=733)$.

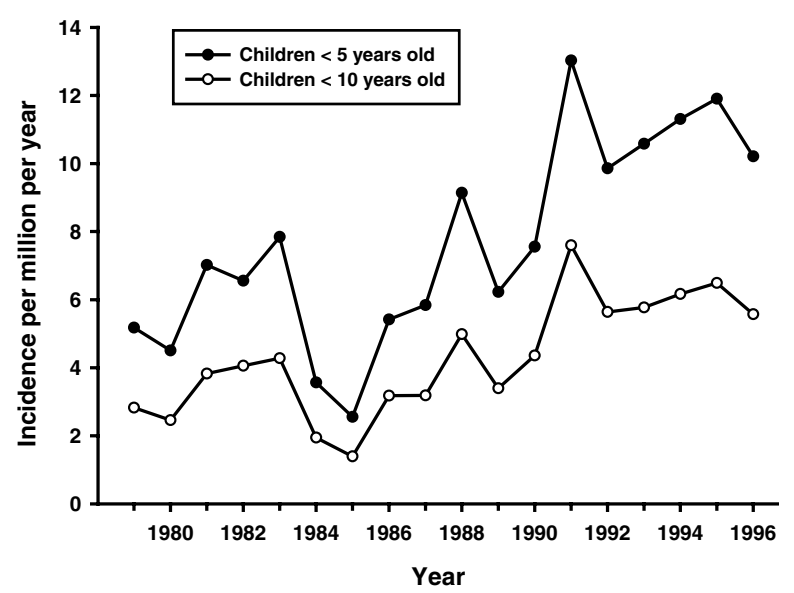

Figure 3 Age-standardized incidence of retinoblastoma in Taiwan from 1979 to $1996(n=259)$.

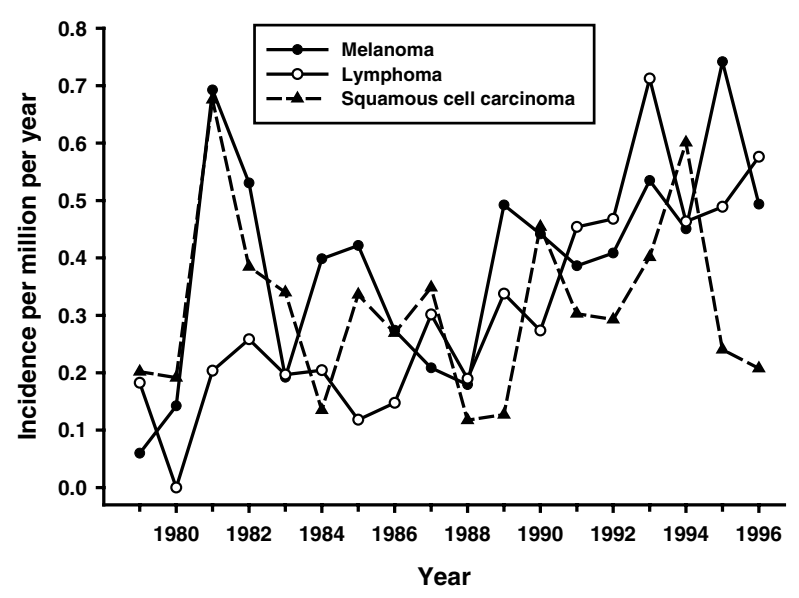

Figure 4 Age-standardized incidence of three common eye cancers - melanoma, lymphoma, and squamous cell carcinoma—in Taiwan from 1979 to 1996. 
Table 4 Age-standardized incidence of eye cancers in selected populations

\begin{tabular}{lccc}
\hline Population & \multirow{2}{*}{ Period } & \multicolumn{2}{c}{ Age-standardized incidence } \\
\cline { 3 - 4 } & & Male & Female \\
\hline New York State $^{1}$ & & 7.5 & 5.4 \\
Canada $^{2}$ & $1975-1986$ & 8.1 & 6.0 \\
Singapore $^{7}$ & $1970-1982$ & 1.89 & 1.81 \\
Taiwan $^{1968-1995}$ & 2.57 & 2.33 \\
\hline
\end{tabular}

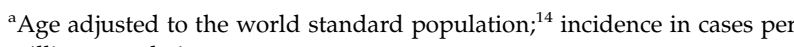
million population.

retinoblastoma, and $9.2 \%$ of squamous cell carcinoma. These relative frequencies of histologic types varied widely between different ethnic populations. It is noteworthy that the three most common eye malignancies in our series only account for $67 \%$ of all cases. This indicated that the susceptibility of the Chinese population to eye cancers may be more heterogeneous.

As compared to Western population, ${ }^{1}$ the frequency of melanoma as one of the most common eye malignancies was relatively lower in the present study. Ocular melanoma mostly affects white individuals or lightly pigmented individuals, and rarely occurs among Asian, black, or Hispanic populations. ${ }^{6,15}$ In Japan, Kaneko ${ }^{16}$ reported that incidence of ocular melanoma was 0.25 per million population. This findings was close to ours (0.39 per million). It is interesting to consider why Asians may be more protected from ocular melanoma. While increased exposure to ultraviolet light has been found to be associated with an increase in cutaneous melanoma, ${ }^{17}$ the evidence for uveal melanoma is still not clear. ${ }^{18,19}$ Nevertheless, the protection of increased pigmentation has been hypothesized to explain the less risk to ocular melanoma in darkly pigmented people when compared with whites people. ${ }^{20}$

In the United States, uveal melanoma primarily affects patients between 60 and 70 years old. ${ }^{6}$ However, it has been observed that Chinese patients with uveal melanoma tended to be younger than their Western counterparts. ${ }^{21}$ This observation was consistent with the present study. The average age of diagnosis was only 48.7 years in our series. In China, the largest number of patients was also in the fifth decade. ${ }^{21}$ Based on these findings, we speculated that Chinese patients may develop uveal melanoma more than 10 years earlier than white individuals. For other Asians, a clinic-based study ${ }^{22}$ in Japan reported that the average age of patients with uveal melanoma was younger (55.2 years) than previously reported for white populations. The reason why there was a younger age distribution of East Asian patients with uveal melanoma was unknown. If increased pigmentation really protects individuals from cumulative carcinogenic exposures to develop melanoma, it would be hard to explain why this malignancy occurs earlier in East Asian than white individuals. Some of the variations in age of onset between ethnic groups could be genetic in origin.

Retinoblastoma was identified as the most common eye malignancy in this Chinese population. This is different from Western populations, among whom melanoma is the most common eye malignancy. ${ }^{1,23}$ The annual incidence of retinoblastoma for children younger than 10 and 5 years was 4.28 and 7.68 per million, respectively, in our study. These estimates were relatively lower than those reported in Western populations. The incidence of retinoblastoma was estimated to be 8.4 per million for children younger than 5 years in Great Britain. ${ }^{24}$ In the United States, the estimated incidence for the same age group was 11 per million in each of the major studies. ${ }^{25-27}$ The annual incidence was 5.8 and 10.9 per million for children younger than 10 and 5 years, respectively, from the SEER (Surveillance, Epidemiology, and End Results) data from 1974 to1985. ${ }^{26}$ In East Asia, data from Singapore Cancer Registry ${ }^{28}$ indicated that the incidence (2.4 per million) for children younger than 10 years was also lower than that in Western populations, but the incidence (11.1 per million) for those before 10 years of age was close to that in the United States. Whether a difference in incidence of retinoblastoma between Asians and white subjects really exists may need further investigation.

Sebaceous gland carcinoma of the eyelids was relatively common in Asians. ${ }^{29}$ This neoplasm usually arises from meibomian or Zeis glands deep within the eyelid, but can rarely be confined to and arises primarily within the conjunctival epithelium. ${ }^{30}$ However, in the present study, we did not identify any case of primary conjunctival sebaceous gland carcinoma. In fact, there is difficulty in documenting the conjunctival origin of sebaceous gland carcinoma. This neoplasm commonly has multicentric origin and, once it becomes invasive, evidence of its precise origin is often obscured. ${ }^{30}$ Therefore, those cases of conjunctival origin might be misjudged histopathologically and misclassified into eyelid malignancy, which was excluded from the present study.

Reliability of population-based cancer incidence data depends on the quality of health services, census figures, and especially the cancer registry system. More than $80 \%$ of the eye cancers in the present study were histologically verified. This compares favourably with the cancer registries in other developed countries. ${ }^{14}$ Based on three data profiles from the Taiwan Cancer Registry, death certificate data from the government's Department of Health, and the Catastrophic Illness Registry in the Taiwan National Health Insurance Program, the 
estimated ascertainment rate of Taiwan Cancer Registry was $90.2 \%$ for the years from 1996 to 1999 (C-J Chen, personal communication, 2003). Although the ascertainment rate in Taiwan Cancer Registry was lower than the rate of $97 \%$ in SEER, ${ }^{31}$ this may be regarded as a minimum estimate, because missed cases subsequently identified by continuing surveillance would be asked to report to the registry system. Moreover, the Taiwan Cancer Registry is believed to be more complete especially in recent years, as medical-care access is no longer a problem since the implementation of the National Health Insurance Program. ${ }^{32}$

The secular trends of cancer incidence and cancer risk differences among ethnic groups may provide researchers with clues for testing the aetiology of, and perhaps preventive methods for, specific malignancies. Comparative research on eye cancers in various races or geographic areas is often limited by low attack rates and rarity of large cancer registries. Data from the Taiwan National Cancer Registry have provided us a unique opportunity to investigate the rare eye cancers in Chinese.

In summary, using data from the Taiwan National Cancer Registry, the present study showed that the incidence of eye cancers among Chinese in Taiwan was relatively lower than that reported form Western populations. The time trends of the incidence of eye cancers were relatively stable over the 18-year period. Retinoblastoma, melanoma, and lymphoma were identified as the three most common eye cancers in this Chinese population.

\section{Acknowledgements}

We thank the Department of Health, the Executive Yuan, Taiwan, for providing the raw data for this study.

\section{References}

1 Mahoney MC, Burnett WS, Majerovics A, Tanenbaum H. The epidemiology of ophthalmic malignancies in New York State. Ophthalmology 1990; 7: 1143-1147.

2 Ayiomamitis A. Epidemiologic features of cancer of the eye, orbit and related adnexa in Canada. Can J Ophthalmol 1989; 24: 269-274.

3 Swerdlow AJ. Epidemiology of eye cancer in adults in England and Wales, 1962-1977. Am J Epidemiol 1983; 1989: 294-300.

4 Devesa SS, Silverman DT, Young Jr JL, Pollack ES, Brown CC, Horm JW et al. Cancer incidence and mortality trends among whites in the United States, 1947-84. J Natl Cancer Inst 1987; 79: 701-770.

5 Foss AJ, Dolin PJ. Trends in eye cancer mortality among adults in the USA and England and Wales. Br J Cancer 1996; 74: $1687-1689$
6 Seddon JM, Egan KM, Gragoudas ES. Epidemiology of uveal melanoma. In: Ryan SJ (ed). Retina. Vol 1, 2nd edn. Mosby: St. Louis, 1994, pp 717-724.

7 Lee SB, Au Eong KG, Saw SM, Chan TK, Lee HP. Eye cancer incidence in Singapore. Br J Ophthalmol 2000; 84: 767-770.

8 Chang MH, Chen CJ, Lai MS, Hsu HM, Wu TC, Kong MS et al. Universal hepatitis B vaccination in Taiwan and the incidence of hepatocellular carcinoma in children. Taiwan Childhood Hepatoma Study Group. N Engl J Med 1997; 336: 1855-1859.

9 Lee CL, Ko YC. Survival and distribution pattern of childhood liver cancer in Taiwan. Eur J Cancer 1998; 34: 2064-2067.

10 Wang PD, Lin RS. Epidemiology of cervical cancer in Taiwan. Gynecol Oncol 1996; 62: 344-352.

11 World Health Organization. Manual of the International Statistical Classification of Diseases, Injuries and Causes of Deaths, Vol 1. World Health Organization: Geneva, 1977.

12 World Health Organization. International Classification of Disease for Oncology, 2nd edn. World Health Organization: Geneva, 1990.

13 Ministry of the Interior, ROC. 1996 Taiwan-Fukien Demographic Fact Book, Republic of China. Ministry of the Interior: Taipei, Republic of China, 1997.

14 Parkin DM, Whelan SL, Ferlay J, Raymond I, Young J (eds). Cancer Incidence in Five Continents. Vol 7. IARC Scientific Publication No. 143, IARC: Lyon, 1998.

15 Hudson HL, Valluri S, Rao NA. Choroidal melanomas in Hispanic patients. Am J Ophthalmol 1994; 118: 57-62.

16 Kaneko A. Japanese contributions to ocular oncology. Int J Clin Oncol 1999; 4: 321-326.

17 Langley RG, Sober AJ. A clinical review of the evidence for the role of ultraviolet radiation in the etiology of cutaneous melanoma. Cancer Invest 1997; 15: 561-567.

18 Holly EA, Aston DA, Char DH, Kristiansen JJ, Ahn DK. Uveal melanoma in relation to ultraviolet light exposure and host factors. Cancer Res 1990; 50: 5773-5777.

19 Seddon JM, Gragoudas ES, Glynn RJ, Egan KM, Albert DM, Blitzer PH. Host factors, UV radiation, and risk of uveal melanoma: a case-control study. Arch Ophthalmol 1990; 108: 1274-1280.

20 Crombie IK. Racial differences in melanoma incidence. Br J Cancer 1979; 40: 185-193.

21 Kuo PK, Puliafito CA, Wang KM, Liu HS, WU BF. Uveal melanoma in China. Int Ophthalmol Clin 1982; 22: $57-71$.

22 Sakamoto T, Sakamoto M, Yoshikawa H, Hata Y, Ishibashi T, Ohnishi $Y$ et al. Histologic findings and prognosis of uveal malignant melanoma in Japanese patients. Am J Ophthalmol 1996; 121: 276-283.

23 Swanson MW, Gloud G. A retrospective analysis of primary eye cancer at the University of Alabama at Birmingham 1958-1988. Part 1: eye and orbital cancer. J Am Optom Assoc 1991; 62: 815-819.

24 Sanders BM, Draper GJ, Kingston JE. Retinoblastoma in Great British 1969-1980: incidence, treatment, and survival. Br J Ophthalmol 1988; 72: 576-583.

25 Tamboli A, Podgor MJ, Horm JW. The incidence of retinoblastoma in the United States: 1974 through 1985. Arch Ophthalmol 1990; 108: 128-132.

26 Pendergrass TW, Davis S. Incidence of retinoblastoma in the United States. Arch Ophthalmol 1980; 98: 1204-1210. 
27 Devesa SS. The incidence of retinoblastoma. Am J Ophthalmol 1975; 80: 263-265.

28 Saw SM, Tan N, Lee SB, Au Eong KG, Chia KS. Incidence and survival characteristics of retinoblastoma in Singapore from 1968-1995. J Pediatr Ophthalmol Strabismus 2000; 37: 87-93.

29 Lee SB, Saw SM, Au Eong KG, Chan TK, Lee HP. Incidence of eyelid cancers in Singapore from 1968 to 1995. Br J Ophthalmol 1999; 83: 595-597.
30 Margo CE, Lessner A, Stern GA. Intraepithelial sebaceous carcinoma of the conjunctival and skin of the eyelid. Ophthalmology 1992; 99: 227-231.

31 Zippin C, Lum D, Hankey BF. Completeness of hospital cancer case reporting form SEER program of the National Cancer Institute. Cancer 1995; 76: 2343-2350.

32 Cheng SH, Chiang TL. The effect of universal health insurance on health care utilization in Taiwan: results from a natural experiment. JAMA 1997; 278: 89-93. 